\title{
Annealing Effects on Breakdown Threshold of Radio-frequency Windows
}

\author{
Shinichiro MICHIZONO ${ }^{1}$, Yoshio SAITO $^{1}$ and Atushi INAGAKI ${ }^{2}$ \\ ${ }^{1}$ KEK, High Energy Accelerator Research Organization, Tsukuba, Ibaraki 305, Japan \\ ${ }^{2}$ NGK Spark Plug Co., Komaki, Aichi 485, Japan
}

(Received January 30, 1997, Accepted April 5, 1997)

\begin{abstract}
The breakdown threshold of alumina rf windows depends not only on the bulk characteristics, but also on surface treatments such as polishing and annealing. Sapphire and alumina-ceramic disks, polished and/or annealed, were examined by high-power tests. The polished disk exhibited a lower threshold value than the annealed one, probably due to its surface charging at defects mechanically introduced by polishing. The elimination of the charged sites present on the surface is considered to be important.
\end{abstract}

\section{Introduction}

The breakdown of alumina rf windows is one of the most serious problems in the development of high-power klystrons. Alumina ceramics have been used as rf-window materials ${ }^{1,2)}$, and several extensive studies of breakdown phenomena have been carried out ${ }^{3-5}$. The results are summarized below.

(1) As a pre-breakdown phenomenon, multipactoring due to a high secondary-electron-emission (SEE) coefficient $(\delta)$ took place together with optical emission (luminescence of alumina) and Xray radiation. The multipactoring electron has a kinetic energy of about $7 \mathrm{keV}$ at a power of $30 \mathrm{MW}$ for a S-band klystron.

(2) Multipactoring induced F-center defects in alumina, which caused rf losses leading to breakdowns such as melting.

(3) Alumina ceramics having low dielectric losses were superior for $\mathrm{rf}$-window materials because they were confirmed not to be liable for an F-center.

(4) Thin-film coatings having a low $\delta$, such as TiN, on alumina ceramics, were confirmed to be effective for the suppression of multipactoring. However, occasional selective flashovers on a TiNcoated surface were observed, accompanied by tree like patterns of alumina luminescence.

A flashover is probably related to surface charg-

* Presented at the XVIIth International Symposium on Discharges and Electrical Insulation in Vacuum, Berkeley, July 21-26, 1996. ing during rf operation. These charges are generally considered to exist in (1) impurities and point defects, such as $\mathrm{F}^{+}-$and $\mathrm{F}$-centers and, (2) other defects, such as dislocation and/or micro cracks ${ }^{6}$. The former depends mainly on the materials, and the latter on the surface treatment, such as machining (lapping or polishing) ${ }^{7}$ ) and annealing.

In this study, the mechanism of the flashover was investigated from the view points of surface treatments. The surface characterizations of charging and defects were performed by the SEE and cathodoluminescence (CL) measurements, respectively.

\section{Results and discussion}

\subsection{Alumina material and surface treatment}

Two kinds of alumina ceramic (UHA-998) and HA-9978) and single-crystal-alumina (sapphire) disks $^{3}$ (92 $\mathrm{mm}$ in diameter and $3.5 \mathrm{~mm}$ thick) were examined. UHA-99 comprises small grains having diameters of about $1 \mu \mathrm{m}$, and has a highly dense structure. HA-997 exhibits lower dielectric losses $(\tan \delta)$ (Table 1).

The disks were lapped with silicon carbide ( $\mathrm{SiC})$ abrasives of 400 and 600 grit for alumina ceramics and sapphire, respectively. Some disks were subjected to polishing using diamond abrasives ( $\sim 2$ $\mu \mathrm{m}$ in diameter) to attain a mirror finish. A sapphire disk, whose surface was chemically etched, was also prepared. Annealing at $1500^{\circ} \mathrm{C}$ for one hour in air ${ }^{9)}$ was carried out for some disks. Photographs of unpolished, polished and annealed surfaces are shown in Fig. 1. The grain boundary of 
Table 1 Surface charging and point defects of the samples

\begin{tabular}{|c|c|c|c|c|c|c|c|c|c|}
\hline & \multicolumn{4}{|c|}{ material } & \multicolumn{3}{|c|}{ Surface } & \multicolumn{2}{|c|}{ before high-power tests } \\
\hline & alumina & $\begin{array}{c}\text { purity } \\
(\%)\end{array}$ & $\varepsilon$ & $\begin{array}{c}\tan \delta \\
\left(\times 10^{-5}\right)\end{array}$ & finish & $\begin{array}{l}\text { Roughness } \\
(\mu \mathrm{m})\end{array}$ & treatment & $\begin{array}{l}\text { charging } \\
\text { type }\end{array}$ & CL spectra \\
\hline$\# 1$ & \multirow{3}{*}{ UHA-99 } & \multirow{3}{*}{99.0} & \multirow{3}{*}{9.81} & \multirow{3}{*}{9.4} & unpolished & 0.6 & none & (a) & $\mathrm{F}^{+}, \mathrm{Cr}^{3+}$ \\
\hline$\# 2$ & & & & & \multirow{2}{*}{ polished } & \multirow{2}{*}{0.1} & annealed & (a) & $\mathrm{F}^{+}, \mathrm{Cr}^{3+}$ \\
\hline$\# 3$ & & & & & & & none & (c) high & $\mathrm{F}^{+}, \mathrm{Cr}^{3+}$ \\
\hline$\# 4$ & \multirow{3}{*}{ HA-997 } & \multirow{3}{*}{99.7} & \multirow{3}{*}{9.95} & \multirow{3}{*}{4.2} & unpolished & 1.4 & none & (a) & $\mathrm{F}^{+}, \mathrm{Cr}^{3+}$ \\
\hline$\# 5$ & & & & & \multirow{2}{*}{ polished } & \multirow{2}{*}{0.1} & annealed & (a) & $\mathrm{F}^{+}, \mathrm{Cr}^{3+}$ \\
\hline$\# 6$ & & & & & & & none & (c) high & $\mathrm{F}^{+}, \mathrm{Cr}^{3+}$ \\
\hline$\# 7$ & \multirow{4}{*}{ sapphire } & \multirow{4}{*}{100} & \multirow{4}{*}{10.2} & \multirow{4}{*}{2.3} & \multirow{2}{*}{ unpolished } & 0.4 & chem.etched & (c) low & mainly $\mathbf{F}$ \\
\hline$\# 8$ & & & & & & 0.25 & none & (c) low & mainly F \\
\hline$\# 9$ & & & & & \multirow{2}{*}{ polished } & \multirow{2}{*}{0.05} & annealed & (a) & $\mathrm{F}^{+}$ \\
\hline$\# 10$ & & & & & & & none & (c) high & mainly $\mathrm{F}$ \\
\hline
\end{tabular}
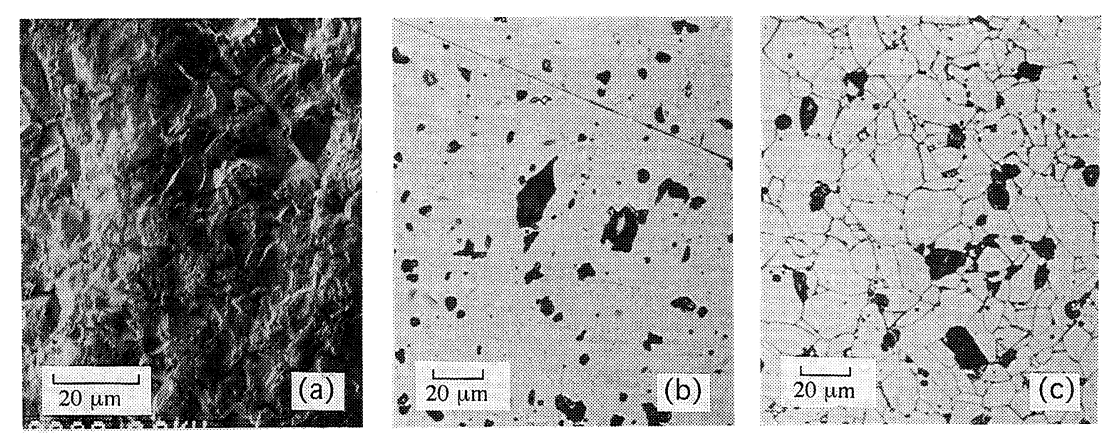

Fig. 1 Microscopic structure of the window material: a) unpolished HA-997 (\#4), (b) polished HA-997 (\#6), and c) annealed HA997 (\#5).

the ceramic after annealing was clearly visible. Rearrangements in the grain probably occurred due to annealing, and the dislocations of the ceramic were considered to be relaxed.

Secondary electron emission (SEE) and cathodoluminescence $(\mathrm{CL})$ were measured in order to investigate the surface conditions before and after a high-power transmission examination using a resonant ring ${ }^{3)}$.

\subsection{Secondary electron emission (SEE) and sur- face charging}

The SEE was measured using a single-pulsed electron beam ( $1 \mathrm{~ms}, 100 \mathrm{pA})$ with a scanning electron microscope (SEM) $)^{2-4)}$, as shown in Fig. 2. The secondary electrons were captured by a biased $(+40$
V) Faraday cup. The relation of the measured currents is

$$
I_{p}=I_{F}+d Q / d t \text {, }
$$

where $I_{p}$ is the primary current, $I_{F}$ is the current captured by the Faraday cup and Q is the amount of charge in the alumina disk. Furthermore,

$$
\mathrm{I}_{\mathrm{ab}}=\mathrm{I}_{\mathrm{p}}-\mathrm{I}_{\mathrm{F}}=\mathrm{dQ} / \mathrm{dt} \text {, }
$$

where $I_{a b}$ is the absorption current. The SEE coefficient $(\delta)$ is given by

$$
\delta=\mathrm{I}_{\mathrm{F}} / \mathrm{I}_{\mathrm{p}} \quad(\mathrm{t}=0) .
$$

SEE measurements were good diagnostics for surface charging. Four typical SEE signals in the measurement are shown in Fig. 3.

(a) $\delta>1$. When surface charging is negligible, secondary emitted electrons are captured by the 


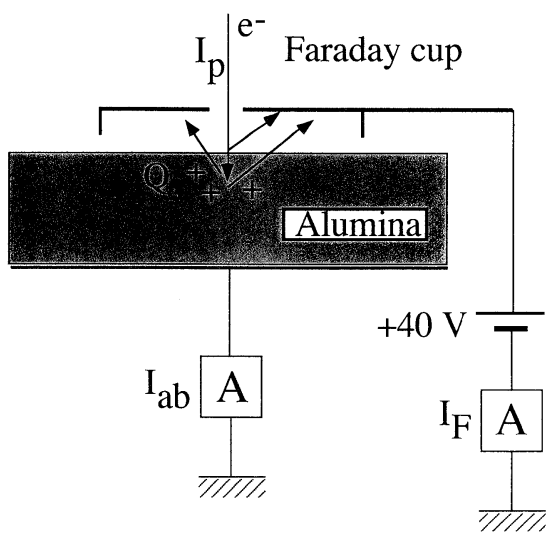

Fig. 2 Schematic of SEE measurements. $I_{p}$ is the primary current, $\mathrm{I}_{\mathrm{F}}$ the secondary electron current captured by Faraday-cup and $\mathrm{I}_{\mathrm{ab}}$ is the absorption current.

Faraday cup $\left(I_{F}>I_{p}\right)$. Positive charging develops with time $(\mathrm{dQ} / \mathrm{dt}>0)$ which recoils secondary electrons to the surface. Thus, $\delta$ decreases rapidly. A small positive charge $(<10 \mathrm{eV})$ is sufficient to draw the electrons, because they have a low kinetic energy of about $1 \sim 5 \mathrm{eV}^{10,11)}$. In fact, the shift of the AES peak was less than $10 \mathrm{eV}$ during an AES analysis of the alumina ceramics. $\mathrm{I}_{\mathrm{F}}$ decreases with time, and finally reaches the value in case (b).

(b) $\delta=1$. The number of secondary electrons captured by the Faraday cup equals that of the primary electrons $\left(I_{F}=I_{p}\right)$. Q does not change $\left(I_{a b}=0\right)$, and this case is the steady state.

(c) $\delta=0$. When the surface is positively charged $(>50 \mathrm{eV})$, all of the secondary electrons released from the surface return to the sample $\left(I_{F}\right.$ $=0$ ). If electron irradiation continues, $Q$ decreases with time and finally also reaches the steady state of case (b).

(d) $\delta=1$. When the surface is negatively charged, the primary electrons are repelled before reaching the sample. This case is also the steady state $(\delta=1)$, and is attained only after electron irradiation to the surface, where $\delta$ is less than unity (the incident energy is $>30 \mathrm{keV}$ for alumina and $>2 \mathrm{keV}$ for TiN coatings, respectively); negative charging $(<-100 \mathrm{eV})$ during an AES analysis of TiN coated alumina was observed at an incident energy of $3 \mathrm{keV}$, which was also reported for $\mathrm{Cu}$ coatings on $\mathrm{MgO}^{12}$.
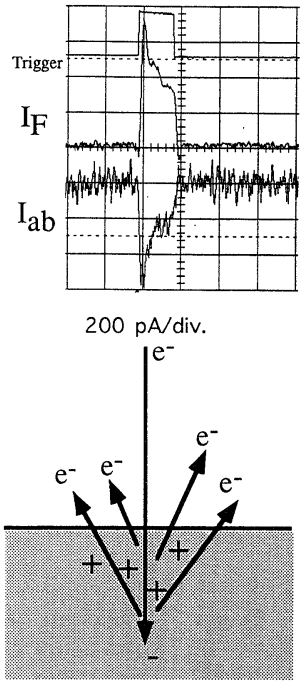

(a) normal surface $\delta>1,|F>| p$, $\mathrm{I}_{\mathrm{ab}}=\mathrm{I}_{\mathrm{p}}-\mathrm{I} \mathrm{F}<0$, $d Q / d t>0$.

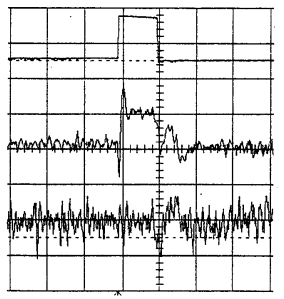

$100 \mathrm{pA} / \mathrm{div}$.

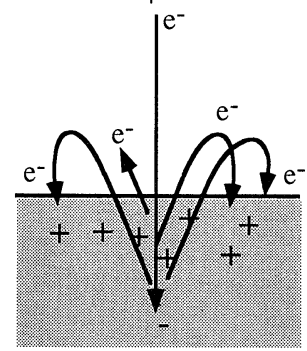

(b) slight positive charging (steady state) $\delta=1, I_{F}=\operatorname{lp}, I_{a b}=0$, $\mathrm{dQ} / \mathrm{dt}=0, \mathrm{Q}>0$.

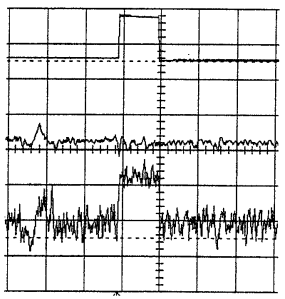

$100 \mathrm{pA} / \mathrm{div}$.

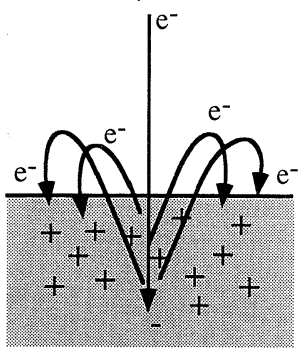

(c) positive charging $\delta=0, I_{F}=0, I_{a b}=I_{p}$, $\mathrm{dQ} / \mathrm{dt}<0, \mathrm{Q}>0$.

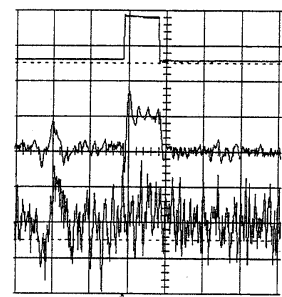

$100 \mathrm{pA} / \mathrm{div}$

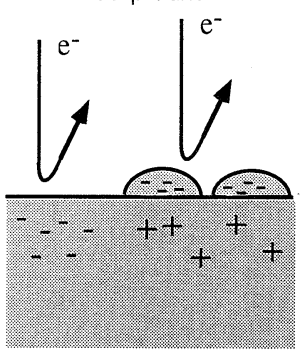

(d) negative charging (steady state) $\delta=1, I F=l_{p}, l_{a b}=0$, $\mathrm{dQ} / \mathrm{dt}=0, \mathrm{Q}<0$.

Fig. 3 SEE signals obtained by a pulsed beam $(1 \mathrm{~ms}, 100 \mathrm{pA})$ at an incident energy of $1 \mathrm{keV}$ together with the schematic of surface charging. Time scale: $1 \mathrm{~ms} /$ div. (a) Normal surface, (b) slight positive charging, (c) positive charging. (d) negative charging, this signal was obtained after $8 \mathrm{keV}$ electron irradiation on TiN-coated area. 
The measured surface charging is summarized in Table 1. All of the polished disks are positively charged. Although surface charging was also observed on unpolished sapphire disks, the charged area was one order of magnitude smaller than that of the polished disks. Polishing is considered to induce charged sites, such as dislocations and/or microcracks, where electrons are removed (thus positive charging).

It is found that the charging due to polishing was removed by annealing. This is caused by the occurrence of electric conduction at high temperatures ${ }^{13}$. The vanishing of surface charges was also interpreted as being caused by a decrease in the number of charged sites due to the relaxation of mechanically introduced dislocations and/or microcracks upon annealing.

\subsection{Cathodoluminescence (CL) and point defects}

The spectra of cathodoluminescence (CL) were observed using a SEM with a $5 \mathrm{keV}$ and a $10 \mathrm{keV}$ electron beam $(20 \mathrm{nA})^{2-4)}$. It is reported that the Fcenter defects (oxygen vacancy having two trapped electrons) contribute to electron emission sites ${ }^{3)}$. On the other hand, the $\mathrm{F}^{+}-$centers (oxygen vacancy having one trapped electron) and impurity levels of $\mathrm{Cr}^{3+}$ (ruby) were not considered to be related to electron emission.

The defects in the sample disks obtained from
$\mathrm{CL}$ are also summarized in Table 1. These pre-existing $\mathrm{F}$-centers depended not on the mechanical treatment, but rather on the type of material.

The sapphire disks have F-center defects which disappeared after annealing. This indicates that electron detrapping due to thermal activation took place upon annealing (the conversion from $\mathrm{F}$-center to $\mathrm{F}^{+}-$or $\alpha$-center) ${ }^{14)}$.

\subsection{High-power if tests and flashover threshold}

High-power transmission tests were performed using a resonant ring ${ }^{3)}$. The surfaces of a dielectric disk were coated with 1 -nm-thick TiN films in three quarters ${ }^{4}$. An $\mathrm{rf}$ window was examined at a maximum power of $230 \mathrm{MW}(2856 \mathrm{MHz}, 2 \mu \mathrm{s}, 50$ pps) in this experiment.

The results are summarized in Table 2.

The flashover thresholds of unpolished disks were higher than those of the polished disks. Although the threshold increased upon annealing, the value did not completely match to that of an unpolished one. This is probably because annealing is insufficient for eliminating all of the charged sites. Sapphire disks showed a lower threshold value than did the ceramic disks due to their preexisting F-centers ${ }^{3}$. For annealed sapphire (\#9), the F-center easily reappeared again during $\mathrm{rf}$ operation at a power of $30 \mathrm{MW}$ or less. Since oxygen defects were possibly converted from $\mathrm{F}^{+}$-centers to $\mathrm{F}$-centers ${ }^{14)}$

Table 2 Polishing and annealing effects on flashover threshold

\begin{tabular}{|c|c|c|c|c|c|c|c|}
\hline & \multirow[b]{2}{*}{ alumina } & \multirow[b]{2}{*}{ finish } & \multirow[b]{2}{*}{ treatment } & \multirow{2}{*}{$\begin{array}{l}\text { threshold } \\
\text { power } \\
\text { (MW) }\end{array}$} & \multicolumn{3}{|c|}{ after high-power tests } \\
\hline & & & & & $\begin{array}{l}\text { charging } \\
\text { type }\end{array}$ & CL spectra & remarks \\
\hline$\# 1$ & \multirow{3}{*}{ UHA-99 } & unpolished & none & $>230$ & (c) high & $\mathrm{F}^{+}, \mathrm{Cr}^{3+},(\mathrm{F})^{*}$ & \\
\hline$\# 2$ & & \multirow{2}{*}{ polished } & annealed & 180 & (c) strong & $\left(\mathrm{F}^{+}, \mathrm{Cr}^{3+}\right)^{* *}$ & crack \\
\hline \#3 & & & none & 145 & (c) strong & $\left(\mathrm{F}^{+}, \mathrm{Cr}^{3+}\right)^{* *}$ & local melting \\
\hline$\# 4$ & \multirow{3}{*}{ HA-997 } & unpolished & none & $>230$ & (c) high & $\mathrm{F}^{+}, \mathrm{Cr}^{3+}$ & \\
\hline$\# 5$ & & \multirow{2}{*}{ polished } & annealed & 230 & (c) high & $\mathrm{F}^{+}, \mathrm{Cr}^{3+}$ & local melting \\
\hline$\# 6$ & & & none & 230 & (c) high & $\mathrm{F}^{+}, \mathrm{Cr}^{3+}$ & pin-hole \\
\hline$\# 7$ & \multirow{4}{*}{ sapphire } & \multirow{2}{*}{ unpolished } & chem. etched & 230 & (c) high & $\mathrm{F}^{+}, \mathrm{F}$ & local melting \\
\hline$\# 8$ & & & none & 160 & $* * *$ & $\mathrm{~F}^{+}, \mathrm{F}$ & local melting \\
\hline$\# 9$ & & \multirow{2}{*}{ polished } & annealed & 100 & $* * *$ & $\mathrm{~F}^{+}, \mathrm{F}$ & local melting \\
\hline$\# 10$ & & & none & 80 & (c) high & $\mathrm{F}^{+}, \mathrm{F}$ & local melting \\
\hline
\end{tabular}

${ }^{*} \mathrm{~F}$-center appeared at the uncoated area.

**There were highly charged areas where CL spectra were difficult to obtain.

*** not measured. 
by trapping of electrons, annealing in air in this experiment is not sufficient to reduce the number of oxygen defects.

Flashovers, which limited the maximum transmission power, were observed on the TiN-coated area on all of the disks, except for \#1 and \#4. Surface melting occurred at the center of the disks after flashovers (Fig. 4).

All of the disks acquired positive charges (case (c)) after the high-power tests on both TiN-coated and noncoated areas, although the intensity of charges depended on the type of disk. It is found that multipactoring resulted in positive charges on the noncoated area. Positive charging on the TiNcoated area is discussed later.

On the highly charged areas generated in highpower tests (\#2 and \#3), the intensity of CL was two orders of magnitude lower than before highpower tests. This implies that charging not only occurred around dislocations and/or microcracks, but also affected the oxygen vacancy.

Surface charging took place after high-power tests, and point defects, in addition to dislocations and/or microcracks, were related to the strong surface charging.

\subsection{Surface charging and flashover}

A model of flashover on a TiN-coated surface can be proposed. TiN coatings suppress multipactoring by absorbing the secondary electrons emitted from alumina. Although the measured $\delta$ is less than unity for the TiN coatings at an incident energy of more than $2 \mathrm{keV}$, the electrons are accumulated in the coatings (case (d) in Fig. 3). The electrons emitted by the applied rf electric field $(8$ $\mathrm{MV} / \mathrm{m}$ under the rf operation at the power of 200 $\mathrm{MW}^{5)}$ ) induce flashover, after which posive charges remain in the disk.

In this model, the threshold value depends on the amount of charges in TiN and the electric field. The amount of charges in TiN was considered to be more when the alumina had a greater number of charged sites. Thus, those polished disks with charged sites introduced by mechanical polishing resulted in a lower threshold. The lower threshold of sapphire was also considered to be due to the fact that the F-center defects contributed to electron emission sites and that more charges were accumulated in TiN.

It is concluded that the elimination of surface charging is important to increase the threshold of flashover.

It is desirable to measure not only the surface but also depth distribution of charges and the electric potential, which is probably related to

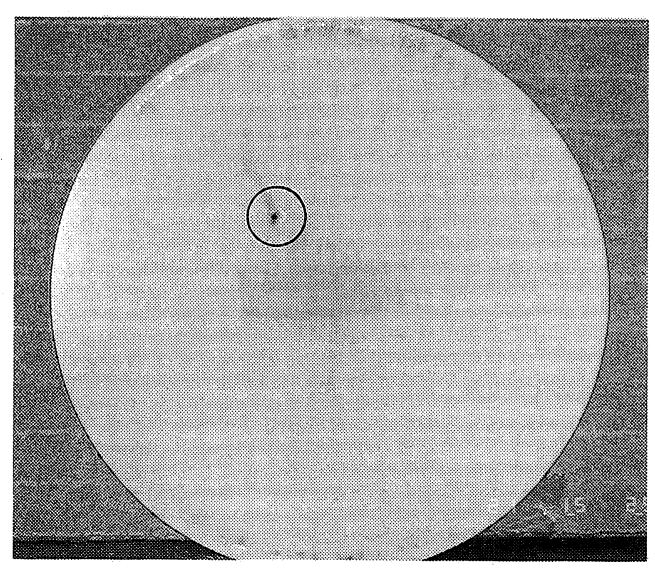

Fig. 4 An alumina disk (\#6) with pinhole after highpower test. Surface melting is observed at the center of the disk.

flashover.

\section{Summary}

The breakdown of alumina rf windows was investigated. Various surface treatments were examined by secondary electron emission (SEE) and cathodo-luminescence (CL). SEE measurements were effective for estimating surface charges, and surface treatments such as polishing and annealing were suggested to affect the charged sites.

The breakdown (flashover) thresholds of the polished disks were lower than those of annealed or unpolished disks due to the accumulation of more charges on the TiN-coated surface, probably released from dislocations and/or microcracks of alumina caused by polishing.

It is concluded that the elimination of surface charging that is due to mechanical polishing was effective in increasing the threshold of flashover. Measurements of the charge distribution and the electric potential suggest the need for further investigations of surface charging and flashover.

\section{References}

1) R. Hayes, "Research on Microwave Window Multipactor and Its Inhibition", Final Report, July 1962 to June 1964, Report\#AD256295, Eitel-McCullough Inc., San Carlos, Cal., June 1964.

2) Y. Saito, IEEE Trans. on Dielectr. and Electr. Insul., 2, 243 (1989).

3) S. Michizono, Y. Saito, S. Yamaguchi, S. Anami, N. Matuda and A. Kinbara, IEEE Trans. on Electr. Insul., 28, 692 (1993).

4) S. Michizono, A. Kinbara, Y. Saito, S. Yamaguchi, 
S. Anami and N. Matuda, J. Vac. Sci. Technol, A10, 1180-1184 (1992).

5) S. Yamaguchi, Y. Saito, S. Anami and S. Michizono, IEEE Trans. on Nucl. Sci., 39, 278 (1992).

6) G. Blaise and C. LeGressus, J. Appl. Phys., 69, 6334 (1991).

7) T. Asokan and T. S. Sudarshan, IEEE Trans. on Dielectr. and Electr. Insul., 1, 97 (1994).

8) NGK Spark Plug Co., Nagoya, Aichi, Japan.

9) A. Berroug, B. Coquillet, S. Fayeulle, B. Hamzaoui, D. Treheux and C. LeGressus, Le Vide, les Couches Minces-Suuplément au n²60 -Janvier-Févri- er, .pp. 427-432, 1992.

10) H. Seiler, J. Appl. Phys., 54, R1 (1983).

11) N. Rey Whetten and A. B. Laponsky, Phy. Rev., 107, 1521 (1957).

12) Preben J. M.ller and Jian-wei HE, Nucl. Inst. Meth. Phys. Res., B17, 137 (1986).

13) W. D. Kingery, H. K. Bowen, and D. R. Uhlmann, "Introduction to Ceramics Second Edition", John \& Sons. Inc., New York, 1976.

14) K. H. Lee and J. H. Crawford, Jr., Phy. Rev B. 19, 3217 (1979). 